\title{
An inexpensive microcomputer peripheral I/O expansion
}

\author{
NAOYUKI OSAKA \\ Otemon-Gakuin University, Ibaraki, Osaka 567, Japan
}

\begin{abstract}
Using a one-chip programmable peripheral interface LSI (8255A), an inexpensive microcomputer (8K PET) peripheral I/O expansion can easily be constructed.
\end{abstract}

Recent developments in microcomputer interfacing techniques make real-time control of experiments relatively inexpensive (Parks, 1978). Peripheral I/O lines are under software control. Usually, these $\mathrm{I} / \mathrm{O}$ device lines are controlled by 8 -bit programmable $1 / 0$ control register within a one-chip interfacing integrated circuit (IC) such as Intel's programmable peripheral interface (PPI) 8255A (24 programmable I/O lines), MOS Technology's peripheral adapter (PA) MCS6520 (16 programmable I/O lines), versatile interface adapter (VIA) MCS6522 (16 programmable I/O lines), and MCS6530 (16 programmable $\mathrm{I} / 0$ lines with $\mathrm{ROM} / \mathrm{RAM}$ and timer), or Motorola's peripheral interface adapter (PIA) MC6820, 6821, 68A21, 68B21 (16 programmable $\mathrm{I} / \mathrm{O}$ lines), and MC6846 (8 programmable $\mathrm{I} / \mathrm{O}$ lines with ROM and timer).

The PET (2001-8 type) ${ }^{1}$ has BASIC-accessible 8-bit parallel I/O lines for laboratory interfacing: Half of the TTL-compatible lines (PA0 to PA7) of the MCS6522VIA remain free as the parallel user port and are directly BASIC accessible using "PEEKing" and "POKEing" at each $\mathrm{I} / \mathrm{O}$ register address (Commodore Business Machines, Inc., 1978). These "built-in" 8-bit I/O lines of the PET have led to the experimental use of real-time laboratory interfaces for connecting switch inputs and outputs to power drivers (or relays) that are simple and inexpensive (McLean, 1978; Osaka, 1979a, 1979b). However, 8-bit I/O lines appear insufficient for the more complex parallel I/O processing, that is, laboratory interfaces for high-resolution $(1,024$ - to 4,096-step) data acquisition system such as $\mathrm{A} / \mathrm{D}$ and $\mathrm{D} / \mathrm{A}$ converting and BCD counting. This insufficient I/O capability to communicate with the outside world has led to the expansion of the programmable $\mathrm{I} / \mathrm{O}$ lines described here. PET's I/O expansion using "builtin" IEEE connector has been reported elsewhere (Lewin \& Helm, 1979). In the system described here, the PET provides 24 (or more) expanded $\mathrm{I} / \mathrm{O}$ lines via an 8255 PPI chip (Intel Corporation, 1979) with four additional NAND gates.

As Figure 1 shows, the logic interface simply consists of two inexpensive IC chips (8255 and 74LSO0). These

This research was supported in part by Research Grant 401059 from the Japan Ministry of Education and by Grant 79-1-072 from the Toyota Foundation.
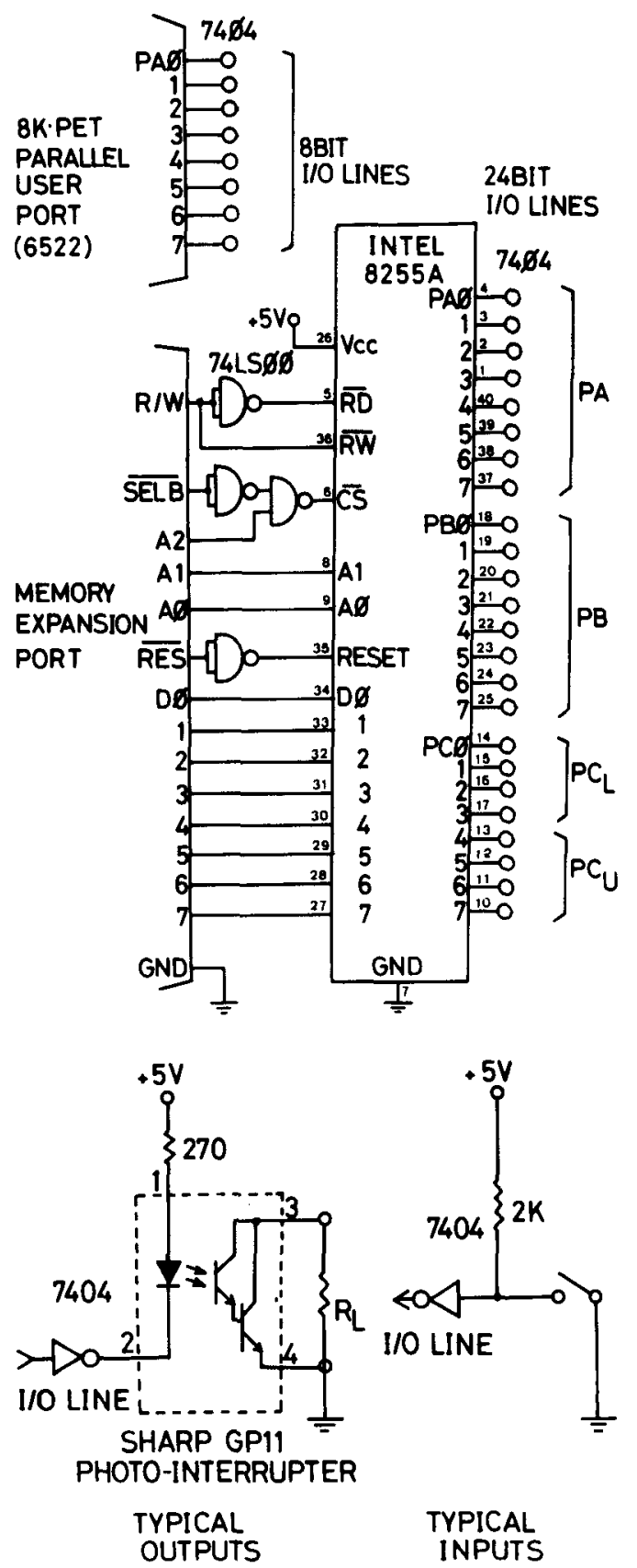

Figure 1. A simple $1 / 0$ expansion using $8255 \mathrm{~A}$ interfacing logic via PET's memory expansion port. 
$24 \mathrm{I} / \mathrm{O}$ lines are also BASIC accessible using "PEEKing" and "POKEing" at each $\mathrm{I} / \mathrm{O}$ register address. Figure 2 indicates $\mathrm{I} / \mathrm{O}$ selection decimal code values and hexadecimal/decimal addresses for each $\mathrm{I} / \mathrm{O}$ handling in the PET memory map. As previously noted, these expanded I/O lines can easily be used in various ways: Figure 3 provides an example BASIC program in which 16-bit (PA and PB ports) and 8-bit (PC port) lines are programmed to operate as input (BCD counter) and output (short-pulse output) lines, respectively. The total cost of the $\mathrm{I} / \mathrm{O}$ expansion interface is less than $\$ 10$.

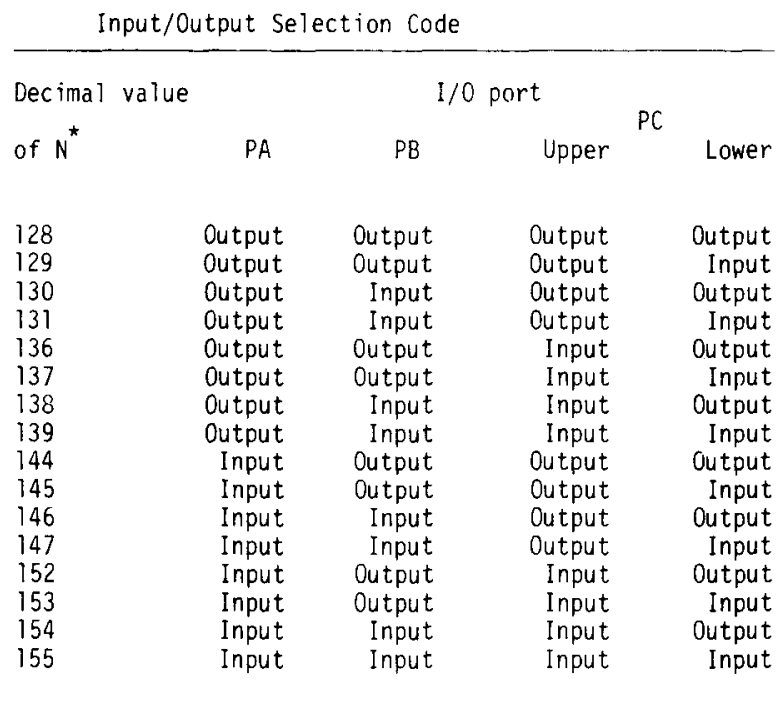
* POKE $45063, N$, where 45063 is decimal address of control
word register (8-bit)

$\begin{array}{lll} & \text { Hexadecimal } & \text { Decimal } \\ & \text { Address } & \text { Address } \\ \text { PA Port } & \text { B004 } & 45060 \\ \text { PB Port } & \text { B005 } & 45061 \\ \text { PC Port } & \text { B006 } & 45062 \\ \text { Control } & & \\ \text { Word Reg. B007 } & 45063\end{array}$

Figure 2. 1/O selection code value $(8255 \mathrm{~A}: \operatorname{mode}=0)$ and hexadecimal/decimal addresses for each $1 / 0$ handling in the PET memory map.

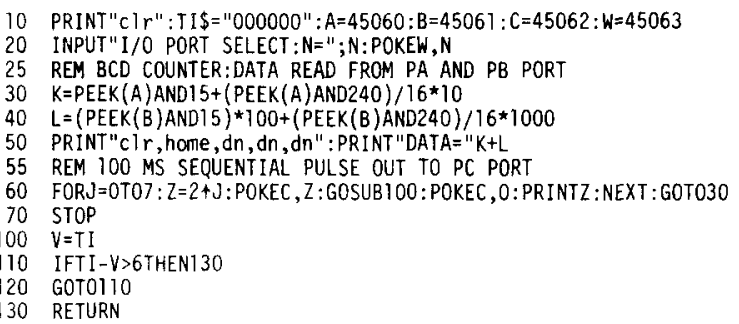

Figure 3. An example BASIC program in which 16-bit (PA and PB) and 8-bit (PC) lines are programmed to operate as input (BCD counter) and output (100-msec pulse out) lines, respectively.

\section{REFERENCES}

Commodore Business Machines, Inc. PET 2001-8 personal computer user manual. Palo Alto, Calif: Author, 1978.

InTEl Corporation. Intel component data catalog. Santa Clara, Calif: Author, 1979

LEWIN, L. M., \& HeLM, G. A versatile microcomputer I/O interface. Behavior Research Methods \& Instrumentation, 1979, 11, 445-446.

McLean, R. S. The Commodore PET: Using personal computers for experimental control. Behavior Research Methods \& Instrumentation, 1978, 10, 468-473.

OsaKA, N. A microprocessor-based real-time BASIC laboratory: A pulse motor-controlled visual stimulator. Behavior Research Methods \& Instrumentation, 1979, 11, 549-552. (a)

OsAKA, N. A microprocessor-based real-time BASIC random interstimulus interval generator with different probability density functions. Behavior Research Methods \& Instrumentation, 1979, 11, 581-584. (b)

Parks, E. R. A general-purpose microcomputer configuration for controlling experiments. Behavior Research Methods \& Instrumentation, 1978, 10, 480-484.

\section{NOTE}

1. It should be noted that the system described here is restricted only to the PET 2001-8 (8K RAM type), which has a memory expansion connector.

(Received for publication December 17, 1979; accepted February 29, 1980.) 